\title{
EFFECT OF DIFFERENT SURFACE FINISHING PROCEDURES ON THE COLOR AND TRANSLUCENCY OF TWO CAD/CAM MONOLITHIC GLASS CERAMICS
}

\author{
Amira El Sharkawy* and Mohammed Moustafa Shalaby**
}

\begin{abstract}
Purpose: The purpose of this study was to investigate the effects of different surface finishing procedures, storage solutions, and prophylactic polishing on the color and translucency parameters (TPs) of two machinable glass ceramics; lithium silicate glass-ceramic (Obsidian)and lithium disilicate reinforced glass-ceramic (IPS e-max CAD).

Materials and Methods: Obsidian and e-max milling blocks were sectioned with a low speed cutting machineunder water cooling into square specimens $\left(10 \times 10 \times 1 \mathrm{~mm}^{3}\right)(\mathrm{N}=60)$. The specimens were divided into 3 groups ( $\mathrm{n}=10$ each) according to the received surface treatment; finishing and polishing, glaze, and staining and glaze in accordance with manufacturers' instructions. Then, each group was further subdivided into 2 storage subgroups, coffee and distilled water as a control ( $\mathrm{n}=5$ for each subgroup). Color and translucency values were measured in CIELAB color space with spectrophotometer at the initial stage, and following 18 days, and after fine-grit prophylactic polishing paste application. Color changes $(\Delta \mathrm{E})$ and translucency $(\Delta \mathrm{TPs})$ were calculated and statistically analyzed using One-way ANOVA for comparing surface treatment followed by Tukey's pair-wise if showed significant. Student t-test was used within material type to show effect of staining. Multifactorial analysis of variance ANOVA was performed to detect significance between variables (material type, surface treatment, immersion solution and re-polish).
\end{abstract}

Results: There was a statistically significant difference between the $\Delta \mathrm{E}$ values of both immersion solutions as $(p=<0.0001<0.05)$ where (coffee $>$ water) for both ceramics tested. Obsidian and e-max, glaze procedure showed lower color change values than finishing and polishing and staining and glazing $\operatorname{surface}(p>0.05)$ following coffee storage. It was found that re-polish decreased color change significantly for both tested ceramics. The translucency was affected according the monolithic CAD/CAM ceramic type. The translucency of the e-max was found to be higher than that of obsidian glass-ceramic. Colorant coffee solution decreased the translucency of both obsidian and e-max ceramics. According to the results of this study, mechanical polishing exhibited highest translucency than stained and glazed and glazed groups. The re-polishing procedure decreased translucency parameter non-significantly for both tested ceramics.

* Assistant professor of Fixed Prosthodontics, ProsthodonticsDepartment, College of Dentistry, Misr University for Science and Technology., Egypt.

** Lecturers of Fixed Prosthodontics, Fixed prosthodontics department, Faculty of Dentistry, Minia University, Egypt. 
Conclusions: Within the limitations of this study, the following conclusions could be drawn: Staining drinks as coffee had a negative effect on the color stability and translucency of both obsidian and e-max glass ceramic materials tested. Glaze procedure led to more color stability with respect to finishing and polishing and stained and glaze for both ceramics after 18 days coffee storage. Polishing paste led to a decrease in color changes for both ceramics tested. The translucency was affected according the monolithic CAD/CAM ceramic type. The translucency of the e-max lithium disilicate glass-ceramic was found to be higher than that of obsidian lithium silicate glass ceramic after different finishing procedure, after coffee storage and after re-polish. Finished and polished groups presented the highest translucency than stained and glazed and glazed for both ceramics tested. Re-polish decreased translucency parameters non-significantly for both tested ceramics.

\section{INTRODUCTION}

All ceramic restorations are frequently preferred in dental treatments, due to the esthetic properties and biocompatibility. Computer-aided design and computer-aided manufacturing (CAD-CAM) systems enable successive production of dental restorations..$^{1-4}$

Full contour monolithic restorations can be designed and manufactured using CAD-CAM machines and materials such as zirconia, zirconia reinforced lithium silicate ceramic, lithium disilicate ceramic, and lithium silicate ceramic. These monolithic restorations, especially which milled from lithium disilicate and lithium silicate glassceramic materials, satisfy the esthetic requirements because of their silicate content. ${ }^{5}$

Among the glass ceramics, the lithium disilicate (LDS) glass ceramic (IPS e.max CAD) has superior optical and mechanical properties than conventional dental ceramics. In recent years, because of the various translucency levels and shades exhibited by LDS ceramics, they have been widely used for monolithic ceramic restorations. ${ }^{6-8}$

Recently, a lithium silicate glass ceramic (Obsidian ceramic) (Glidewell Dental Laboratories, Newport Beach, CA, USA) is newly introduced to the market. After crystallization, it exhibits an ideal mixture of esthetics and strength with translucency that reflects the vitality of natural teeth for fabrication of anterior and posterior crowns. Obsidian ceramic restorations are highly resistant to chipping unlike other ceramics, due to their monolithic composition and average flexural strength of $385 \mathrm{MPa}$. Obsidian milling block characterized by good wear resistance due to a very high content of ultrafine nanometersize crystalline structure. According to the producer; Obsidian is a combination of over 20 elemental oxides including zirconia. Also, it comprisesa high content of ultrafine nano-meter size lithium silicate and lithium phosphate crystals. ${ }^{9}$

An ultimate aesthetic restoration should be morphologically and optically harmonious with the natural teeth. All ceramic restorations offer an aesthetic appearance close to the natural optical properties of the tooth structure ${ }^{10,11}$ This desired natural appearance is not always achievable due to difficulties in matching the natural tooth color with the existing tooth porcelains. ${ }^{12-14}$ Hue, chroma, value, and translucency/opacity are color elements that affect the aesthetics of dental restorations ${ }^{14,15}$ Since human enamels have a natural translucency, aesthetic materials must reproduce the translucency of natural teeth ${ }^{16,17}$ aesthetic ceramics must have high translucency in order to simulate the natural tooth structure. ${ }^{18}$ The translucency parameter (TP) and contrast ratio (CR) are used to measure translucency of dental materials. ${ }^{19}$ Also, the ceramic materials of fixed dental prostheses must offer longterm color stability to avoid repetitive restoration. 
Multicolored CAD/CAM blocks have been developed to overcome the esthetic mismatch between the restoration and natural tooth. ${ }^{20}$ Additional external staining may be required for restoration characterization in some cases. ${ }^{21}$ Although the manufacturers recommend glazing or polishing for lithium disilicate and lithium silicate monolithic restorations to improve esthetics, but color stability and translucency after glazing or polishing are still unclear.

Polishing of dental restorations using prophylactic pastes is required to remove biofilm and extrinsic stains and to achieve a smooth glossy surface. Previous researches found higher surface roughness on composite resins compared with base line after polishing with prophylactic pastes. ${ }^{22,23}$ However, information regarding the effect of prophylactic pastes on ceramics is limited in the dental works. ${ }^{24}$ Therefore, the aim of the present study was to investigate the effects of different surface finishing procedures, staining solution and prophylactic polishing on the color and translucency of monolithic lithium silicate glass-ceramic (Obsidian) and lithium disilicate reinforced glass-ceramic( IPS E-max) .

The null hypotheses of this study were that (1) the various finishing procedures (the finishing and polishing, glaze, and/or staining and glaze) would not result in a difference in color and translucency of the lithium disilicate, and lithium silicate machinable glass ceramics (2) the storage in staining drinks would have no effect on the color and relative translucency of the tested CAD/CAM ceramics, and (3) the polishing paste application would has no effect on coffee discoloration if occurred.

\section{MATERIALS AND METHODS}

Two types of CAD-CAM glass-ceramic ( $\mathrm{N}=60)$, a lithium silicate glass-ceramic (obsidian) $(n=30)$ and a lithium disilicate glass-ceramic (IPS e.max CAD; Ivoclar Vivadent AG) $(n=30)$, were tested for color and translucency changes. The compositions of the materials are presented in Table 1. Specimens were randomly divided into 3 surface finishing procedure groups, namely; finishing and polishing, glazing, and external staining and glaze ( $\mathrm{n}=10$ /group). Using the CAD software (Dental CNC, v6.17.00), a design was created that outfits the dimension of the milling blocks for both the obsidian and e-max (Fig.1). Partially crystallized milling blocks were sectioned by using a low speed cutting machine (isomet 4000 , Buehler, Germany) to obtain square plates of; 10 $\times 10 \times 1 \mathrm{~mm}^{3}$ dimensions (Fig. 2). Each specimen had a handle to allow for accurate positioning during staining and glazing. The thicknesses of each ceramic specimen were checked by using a

TABLE (1) The brand names, manufacturers, chemical compositions and batch numbers of the ceramic materials used in the study:

\begin{tabular}{|c|c|c|c|}
\hline Brand & Manufacturer & Chemical composition & Batch number \\
\hline $\begin{array}{l}\text { IPS e.max } \\
\text { CAD }\end{array}$ & $\begin{array}{l}\text { Ivoclar Vivadent, } \\
\text { Schaan, } \\
\text { Liechtenstein }\end{array}$ & $\begin{array}{l}\text { Lithium disilicate } \\
\text { glass-ceramic, } \\
\mathrm{SiO}_{2}(57-80), \mathrm{Li} 2 \mathrm{O} \\
(11-19), \mathrm{K} 2 \mathrm{O}(0-13), \\
\mathrm{P} 2 \mathrm{O} 5(0-11), \\
\mathrm{ZrO} 2(0-8), \mathrm{ZnO} \\
(0-8), \text { and other } \\
\text { coloring oxides } \\
(0-12)\end{array}$ & U51702 \\
\hline Obsidian milling blocks & $\begin{array}{lll}\text { Prismatik } & \text { Dentalcraft, } & \text { Inc. } \\
\text { Irvine,USA } & & \end{array}$ & More than 20 metal oxides and zirconia & $16-237-0896$ \\
\hline
\end{tabular}




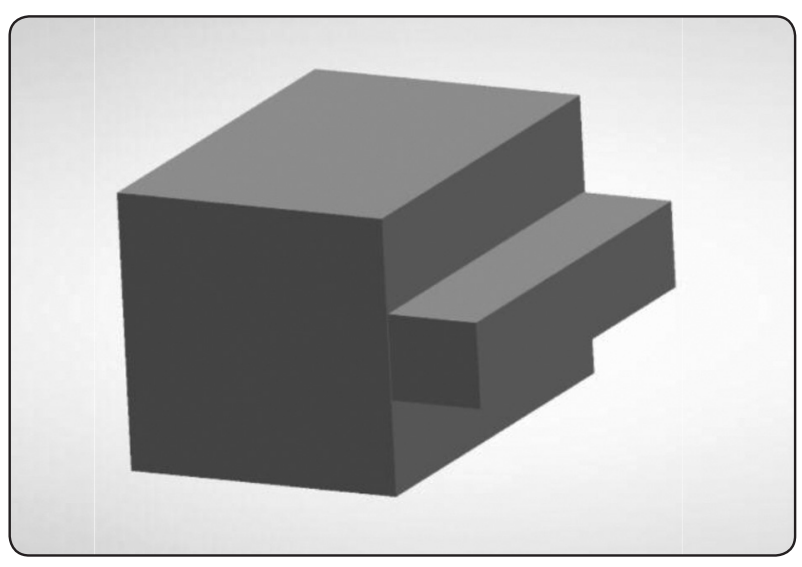

Fig. (1) A design created that suits the dimension of the Obsidian and IPSe-max milling blocks.

digital caliper.High translucency blocks were used in this study. A3 shade milling blocks were selected for both finishing and polishing, and glaze groups. Whereas A1 shade blocks were used for staining and glazing groups. A1 shade was chosen, so that after the staining and glazing firing, all the specimens in each group had A3 shade. For the obsidian samples in all groups, all finishing procedures must be done before crystallization as recommended by the manufacturer.

After finishing and prior to crystallization, the restoration should be thoroughly cleaned with a steam jet. The partially crystallized ceramic specimens in e-max and obsidian material groups were subjected to crystallization firing cycle according to the manufacturer's instructions(Programat P3010; Ivoclar Vivadent) at $820^{\circ} \mathrm{C}$ for 10 minutes and at $850^{\circ} \mathrm{C}$ for 10 minutes, respectively to improve their mechanical properties. The specimens were supported on the try during firing using vita firing paste. (Fig. 3)

The obsidian and e-max specimens were divided into 3 groups according to the surface treatments they received, finishing and polishing, glazing and staining and glaze.

All surface treatments were applied to all the surfaces of the specimen and to the handle. For the

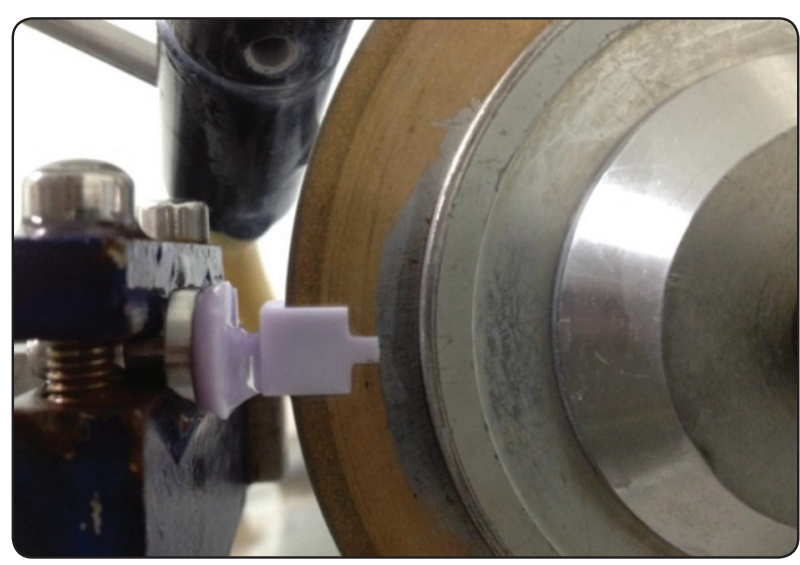

Fig. (2) Partially crystallized milling blocks were sectioned by using a low speed cutting machine.

glaze groups, the specimens in the e.max group were finished using finishing wheel (the green wheel of the Eve Diapol, EvE Ernst Vetter GmbH Rastatter Str, Pforzhei) then cleaned using steam jet. Finally the specimens of the 2 groups were glazed according to the manufacturers' instructions, by using the suitable glaze porcelain. (IPS Ivoclar, vivadent, Glaze) was used for e-max glaze group, whereas (VITA Akzent Plus, VITA Zahnfabrik, Germany) was used for the Obsidian glaze group.

For the finishing and polishing groups, the specimens were polished by using a slow-speed straight hand-piece (NSK EX-6B, Japan). The hand piece was mounted to a special device to ensure standardization of grinding pressure, direction and rate to which the samples were subjected to. The e-max ceramic specimens were finished and polished using (Eve Diapol, EvE Ernst Vetter GmbH Rastatter Str, Pforzheim). The first step was the finishing using the green polishing discs (medium) approx. 35 microns. Then the grey wheel (fine) approx. 4-8 microns was used for smoothing and pre-polish. Finally the pink wheel (extra fine) approx. 1-2 microns was used for high luster polishing. All the finishing and polishing procedures were carried out at a recommended speed of 7000 RPM. Each step was done for 1 minute.

The specimens in the obsidian ceramic group were polished with a polishing kit (Eve Diapol). 


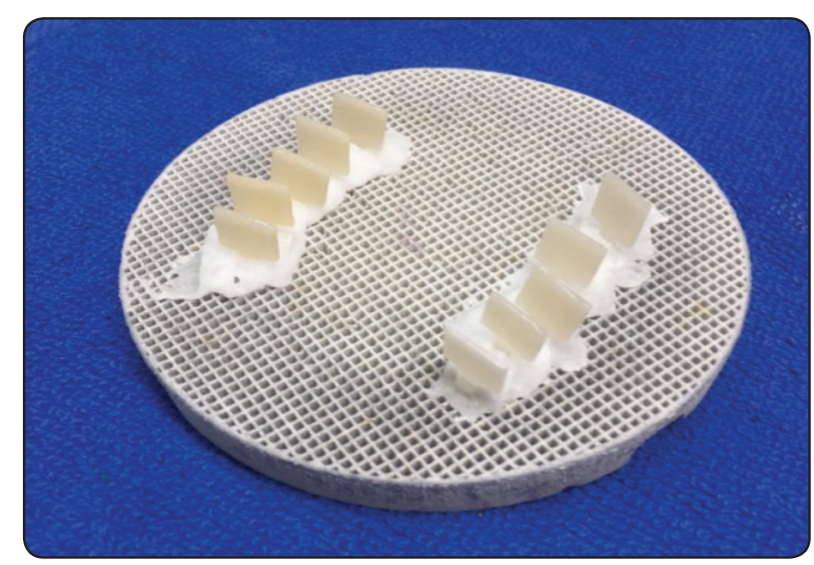

Fig. (3) The specimens were supported on the tray during firing using vita firing paste.

The first step was smoothness and pre-polish using the grey wheel, then luster polishing was performed using the pink wheel. All the polishing procedures were carried out at a recommended speed of 7000 RPM. Each step was done for 1 minute.

For the external stain and glaze groups, the specimens of the e.max group were finished as those in the glaze group. The staining materials (IPS Ivocolor Shade and Vita Akzent Plus Effect Stains) were used for e-max and obsidian stain and glaze groups respectively; and glaze porcelains (IPS Ivocolor Glaze and Vita Akzent Plus) for e-max and obsidian respectively. The external stain was brushed in the beginning, then glaze was applied. The specimens were fired in one firing cycle in accordance with the recommended firing procedures. After firing, the color of the specimens was checked using dental spectrophotometer device (VITA Easyshade Advance; Vita Zahnfabrik) to be A3.

\section{Color measurement}

Initial color values of all specimens were measured in CIELAB color space withspectrophotometer (Cary 5000, Agilent Technologies, USA) under D65 illumination on a black background. ${ }^{25}$ LAB color space, which was defined by the Commission International D' Eclairage (CIE), is used for measurement of color values. $\mathrm{L}^{*}$ represents the lightness (i.e., the gray scale from black to white), the parameter $a^{*}$ represents the chromaticity varying from greenness (negative) to redness (positive), whereas the $b^{*}$ parameter shows the chromaticity varying from blueness (negative) to yellowness (positive). ${ }^{25}$ The spectrophotometer was calibrated before the measurement according to the manufacturer's instructions.

Translucency was determined by finding the value of the TPs ( translucency parameters).Measurements was achieved with the spectrophotometer on white and black backgrounds, and the mean CIE L*a*b* values were recorded for both backgrounds. The TPs was found by calculating the difference in color between the specimen over a white and black background with the following formula: ${ }^{10,26}$

$$
\mathrm{TP}=\left(\left(\mathrm{L}^{*}{ }_{\mathrm{B}}-\mathrm{L}_{\mathrm{w}}^{*}\right)^{2}+\left(\mathrm{a}_{\mathrm{B}}^{*}-\mathrm{a}_{\mathrm{w}}{ }_{\mathrm{w}}\right)^{2}+\left(\mathrm{b}_{\mathrm{B}}{ }_{\mathrm{B}}-\mathrm{b}_{{ }_{\mathrm{w}}}\right)^{2}\right)^{1 / 2}
$$

In this formula, $B$ signifies the color coordinates over a black background and W signifies the color coordinates over a white background. The greater the TP value, the higher the translucency of the material.

Each group was further subdivided into 2 subgroups according to the storage media either coffee or distilled water as a control ( $n=5 /$ subgroup). The coffee solution was prepared with $1.2 \mathrm{gm}$ coffee (Nescafe Classic; Nestle, Spain) was dissolved in 100 $\mathrm{mL}$ of boiling distilled water for each subgroup. The solution was stirred every $8 \pm 1$ hours and changed every 24 hours $^{27,28}$ by the same operator. Finally, distilled water served as the control subgroups solution. All specimens were stored in $100 \mathrm{ml}$ solutions for each subgroup at room temperature for 18 days. Then the specimens were rinsed with distilled water for 5 minutes and blotted dry with tissue paper before color measurements. The second set of color and translucency measurements were made using the spectrophotometer with the same method as the first. The determination of the color variation, $\Delta \mathrm{E}^{*}$, between the two color measurements was made in the CIE L*a*b* system using the following equation: $\Delta \mathrm{E}=\left[\left(\mathrm{L}_{1}^{*}-\mathrm{L}_{2}^{*}\right)^{2}\right.$ $\left.+\left(a_{1}^{*}-a_{2}{ }^{*}\right)^{2}+\left(b_{1}^{*}-b_{2}{ }^{*}\right)^{2}\right]^{1 / 2} \cdot L_{1}^{*}, a_{1}^{*}$, and $b_{1}^{*}$ 
represent the initial color values of the specimens, and $\mathrm{L}_{2}{ }^{*}, \mathrm{a}_{2}{ }^{*}$, and $\mathrm{b}_{2}{ }^{*}$ represent the measurement after beverage storage.

Polishing paste (Proxyt fine RDA 7; Ivoclar Vivadent) was applied on all surfaces of all the specimens in all subgroups, by using rubber cups and polished by using a slow-speed hand-piece (Kavo Ewl 4990; Kavo Dental Gmbh, Germany) at a speed of 10,000RPM, for 1 minute; the hand piece was mounted to a special device to ensure standardization of grinding pressure, direction and rate to which the samples were subjected. The specimens were polished in one direction in dry environment. Then, the specimens were cleaned with distilled water and alcohol. After this, the color and translucency measurements were performed again with the spectrophotometer. The color and the translucency values for all subgroups before immersion and after immersion in storage media, and after polishing were plotted and statistically analyzed.

\section{Statistical Analysis}

The results were analyzed using Graph Pad Instat (Graph Pad, Inc.) software for windows. A value of $\mathrm{P} \leq 0.05$ was considered statistically significant. Continuous variables were expressed as the mean and standard deviation. After homogeneity of variance and normal distribution of errors had been confirmed, One-way ANOVA was done for compared surface treatment followed by Tukey's pair-wise if showed significant. Student t-test was used within material type to show effect of staining. Multifactorial analysis of variance ANOVA was performed to detect significance between variables (material type, surface treatment, immersion solution and repolish). Sample size $(n=5)$ was large enough to detect large effect sizes for main effects and pair-wise comparisons, with the satisfactory level of power set at $80 \%$ and a $95 \%$ confidence level.

\section{RESULTS}

\section{Color changes}

Descriptive statistics showing mean values and standard deviation of color changes test results measured in $(\Delta \mathrm{E})$ as function of surface treatment after coffee, distilled water immersion and re-polish are summarized in (Table 2) and graphically drawn in Fig. (4).

Ceramic material group; totally regardless to surface treatment, immersion solution or re-polish it was found that there was no-significant difference between both ceramic material groups as indicated by multi-factorial ANOVA test $(\mathrm{p}=0.2092>0.05)$ where (Obsidian $\geq e$. max $)$

Surface treatment; Irrespective of material group, immersion or re-polish, totally it was found that there was no-significant difference between all surface treatment as indicated by multi-factorial ANOVA test $(\mathrm{p}=0.9163>0.05)$ where $($ Finished $\&$ polished $\geq$ Stained \& glazed $\geq$ Glazed)

Immersion solution; totally regardless to ceramic material group, surface treatment or re-polish it was found that there was significant difference between both immersion solutions as indicated by multifactorial ANOVA test $(\mathrm{p}=<0.0001<0.05)$ where (coffee $>$ water)

Effect of re-polish; with both groups totally it was found that re-polish decreased color change significantly as indicated by multi-factorial ANOVA test $(\mathrm{p}=0.0256<0.05)$ where $(\boldsymbol{r}$ - -polish $>$ staining solution)

\section{Translucency parameters (TPs)}

Translucency parameters (TPs) results showing mean and standard deviation (SD), values for both material types with different surface treatment after coffee, water immersion and re-polish are summarized in Table (3) and graphically drawn in Fig (5).

Ceramic material group; totally regardless to surface treatment, immersion solution or re-polish 
TABLE (2) Comparison of color changes test results (Mean \pm SD) for both ceramic groups with different surface treatment after coffee, water immersion and re-polish.

\begin{tabular}{|c|c|c|c|c|c|}
\hline \multirow{2}{*}{\multicolumn{2}{|c|}{ Variables }} & \multicolumn{3}{|c|}{ Surface treatment } & \multirow{3}{*}{$\begin{array}{c}\text { ANOVA } \\
\text { P value } \\
0.049^{*}\end{array}$} \\
\hline & & \multirow{2}{*}{$\begin{array}{c}\text { Finished\& polished } \\
2.93{ }^{{ }^{\mathrm{A}} \pm 0.25}\end{array}$} & \multirow{2}{*}{$\begin{array}{c}\text { Glazed } \\
2.37^{\mathrm{B}} \pm 0.21\end{array}$} & \multirow{2}{*}{$\begin{array}{c}\text { Stained \& glazed } \\
2.93^{\mathrm{A}} \pm 0.28\end{array}$} & \\
\hline \multirow{4}{*}{ e. $\max$} & Coffee & & & & \\
\hline & Re-polish & $2.17^{\mathrm{A}} \pm 0.12$ & $2.2^{\mathrm{A}} \pm 0.1$ & $2.46^{\mathrm{A}} \pm 0.2$ & $0.1164 \mathrm{~ns}$ \\
\hline & Water & $0.16^{\mathrm{A}} \pm 0.015$ & $0.17^{\mathrm{A}} \pm 0.02$ & $0.13^{\mathrm{A}} \pm 0.01$ & $0.0545 \mathrm{~ns}$ \\
\hline & Re-polish & $0.15^{\mathrm{A}} \pm 0.011$ & $0.17^{\mathrm{A}} \pm 0.012$ & $0.14^{\mathrm{A}} \pm 0.01$ & $0.052 \mathrm{~ns}$ \\
\hline \multirow{4}{*}{ Obsidian } & Coffee & $3.34^{\mathrm{A}} \pm 0.33$ & $2.38^{\mathrm{B}} \pm 0.21$ & $2.74^{\mathrm{B}} \pm 0.24$ & $0.009 *$ \\
\hline & Re-polish & $3.16^{\mathrm{A}} \pm 0.29$ & $2.33^{\mathrm{B}} \pm 0.13$ & $2.45^{\mathrm{B}} \pm 0.12$ & $0.004 *$ \\
\hline & Water & $0.15^{\mathrm{A}} \pm 0.014$ & $0.18^{\mathrm{A}} \pm 0.016$ & $0.19^{\mathrm{A}} \pm 0.02$ & $0.0659 \mathrm{~ns}$ \\
\hline & Re-polish & $0.14^{\mathrm{A}} \pm 0.01$ & $0.16^{\mathrm{A}} \pm 0.015$ & $0.18^{\mathrm{A}} \pm 0.05$ & $0.4169 \mathrm{~ns}$ \\
\hline
\end{tabular}

*; significant $(p<0.05) n s ;$ non-significant $(p>0.05)$

Different letter in the same row indicating statistically significant difference $(p<0.05)$

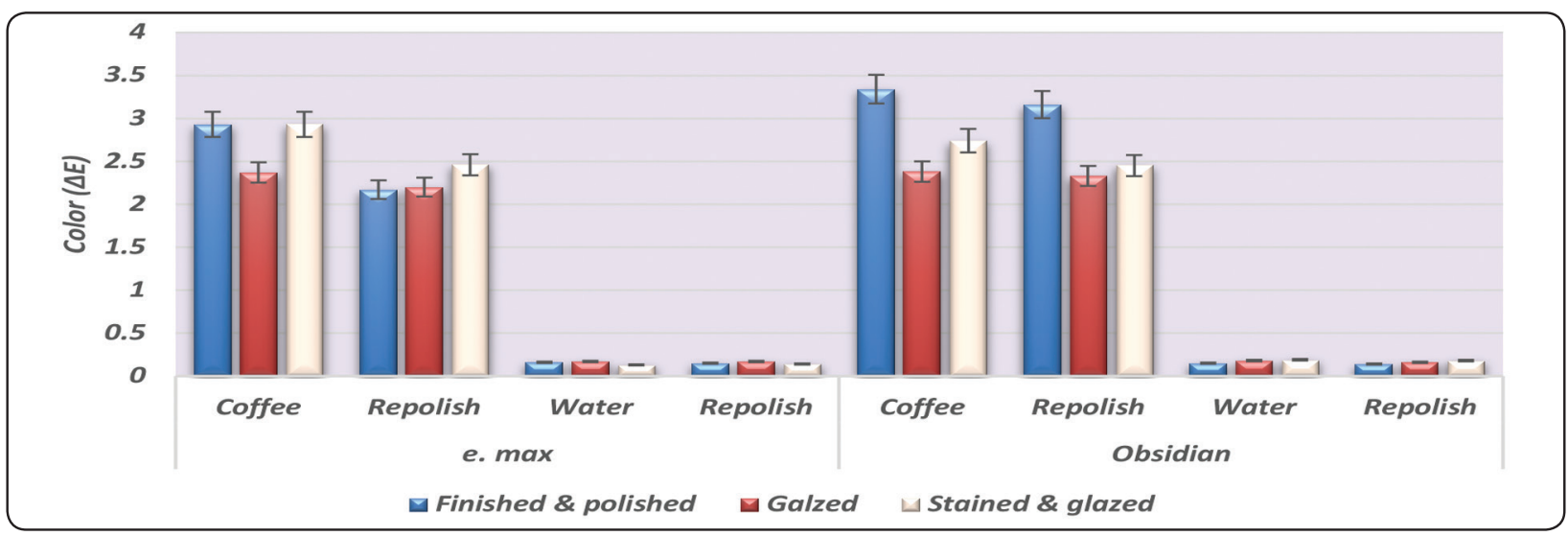

Fig. (4) Column chart showing the mean values of color changes for both ceramic groups with different surface treatment after coffee, water immersion and re-polish

it was found that there was significant difference between both ceramic material groups as indicated by multi-factorial ANOVA test $(\mathrm{p}=<0.0001<0.05)$ where (e. max $>$ Obsidian)

Surface treatment; Irrespective of material group, immersion or re-polish, totally it was found that there was significant difference between all surface treatment as proved by multi-factorial ANOVA test $(\mathrm{p}=<0.0001<0.05)$ where $($ Finished\& polished $\geq$ Stained \& glazed $>$ Glazed)
Immersion solution; totally regardless to ceramic material group, surface treatment or re-polish it was found that there was significant difference between both immersion solutions as indicated by multifactorial ANOVA test $(\mathrm{p}=0.0389<0.05)$ where (water $>$ coffee $)$

Effect of re-polish; with both groups totally, it was found that re-polish decreased translucency parameter non-significantly as indicated by multifactorial ANOVA test $(\mathrm{p}=0.937<0.05)$ where (baseline $\geq$ immersion solution $\geq$ re-polish ). 
TABLE (3) Comparison of translucency parameter test results (Mean \pm SD) for both ceramic groups with different surface treatment after coffee, water immersion and re-polish.

\begin{tabular}{|c|c|c|c|c|c|c|}
\hline & \multirow{2}{*}{\multicolumn{2}{|c|}{ Variables }} & \multicolumn{3}{|c|}{ Surface treatment } & \multirow{3}{*}{$\begin{array}{c}\text { ANOVA } \\
\text { P value } \\
0.003^{*}\end{array}$} \\
\hline & & & Mechanicalpolished & Galzed & Stained \& glazed & \\
\hline \multirow{6}{*}{ e. $\max$} & \multirow{3}{*}{ Coffee } & Baseline & $20.94^{\mathrm{A}} \pm 3.53$ & $18.9^{\mathrm{B}} \pm 2.3$ & $14.24^{\mathrm{C}} \pm 1.02$ & \\
\hline & & Immersed & $19.78^{\mathrm{A}} \pm 4.11$ & $17.86^{\mathrm{B}} \pm 3.15$ & $11.56^{\mathrm{C}} \pm 0.96$ & $0.0028 *$ \\
\hline & & Re-polish & $20.32^{\mathrm{A}} \pm 4.34$ & $17.96^{\mathrm{B}} \pm 3.16$ & $11.64^{\mathrm{C}} \pm 1.18$ & $0.002 *$ \\
\hline & \multirow{3}{*}{ Water } & Baseline & $21.22^{\mathrm{A}} \pm 3.51$ & $18.65^{\mathrm{B}} \pm 2.23$ & $14.2^{\mathrm{C}} \pm 1.29$ & 0.003 \\
\hline & & Immersed & $21.16^{\mathrm{A}} \pm 3.5$ & $18.63^{\mathrm{B}} \pm 2.24$ & $14.16^{\mathrm{C}} \pm 1.27$ & $0.002 *$ \\
\hline & & Re-polish & $21.21^{\mathrm{A}} \pm 3.52$ & $18.63^{\mathrm{B}} \pm 2.23$ & $14.17^{\mathrm{C}} \pm 1.30$ & $0.003^{*}$ \\
\hline \multirow{6}{*}{ Obsidian } & \multirow{3}{*}{ Coffee } & Baseline & $14.87^{\mathrm{A}} \pm 2.29$ & $13.58^{\mathrm{A}} \pm 1.65$ & $10.29^{\mathrm{B}} \pm 0.65$ & $0.01 *$ \\
\hline & & Immersed & $13.95^{\mathrm{A}} \pm 2.04$ & $12.94^{\mathrm{A}} \pm 1.53$ & $9.88^{\mathrm{B}} \pm 0.51$ & 0.003 \\
\hline & & Re-polish & $14^{\mathrm{A}} \pm 2.03$ & $13.03^{\mathrm{A}} \pm 1.55$ & $9.94^{\mathrm{B}} \pm 0.49$ & $0.0028^{*}$ \\
\hline & \multirow{3}{*}{ Water } & Baseline & $14.71^{\mathrm{A}} \pm 2.16$ & $13.54^{\mathrm{A}} \pm 1.57$ & $10.4^{\mathrm{B}} \pm 0.59$ & $0.002^{*}$ \\
\hline & & Immersed & $14.64^{\mathrm{A}} \pm 2.14$ & $13.51^{\mathrm{A}} \pm 1.57$ & $10.37^{\mathrm{B}} \pm 0.57$ & 0.003 \\
\hline & & Re-polish & $14.69^{\mathrm{A}} \pm 2.16$ & $13.54^{\mathrm{A}} \pm 1.58$ & $10.38^{\mathrm{B}} \pm 0.58$ & $0.002 *$ \\
\hline
\end{tabular}

*; significant $(p<0.05) n s ;$ non-significant $(p>0.05)$ Different letter in the same row indicating statistically significant difference $(p<0.05)$.

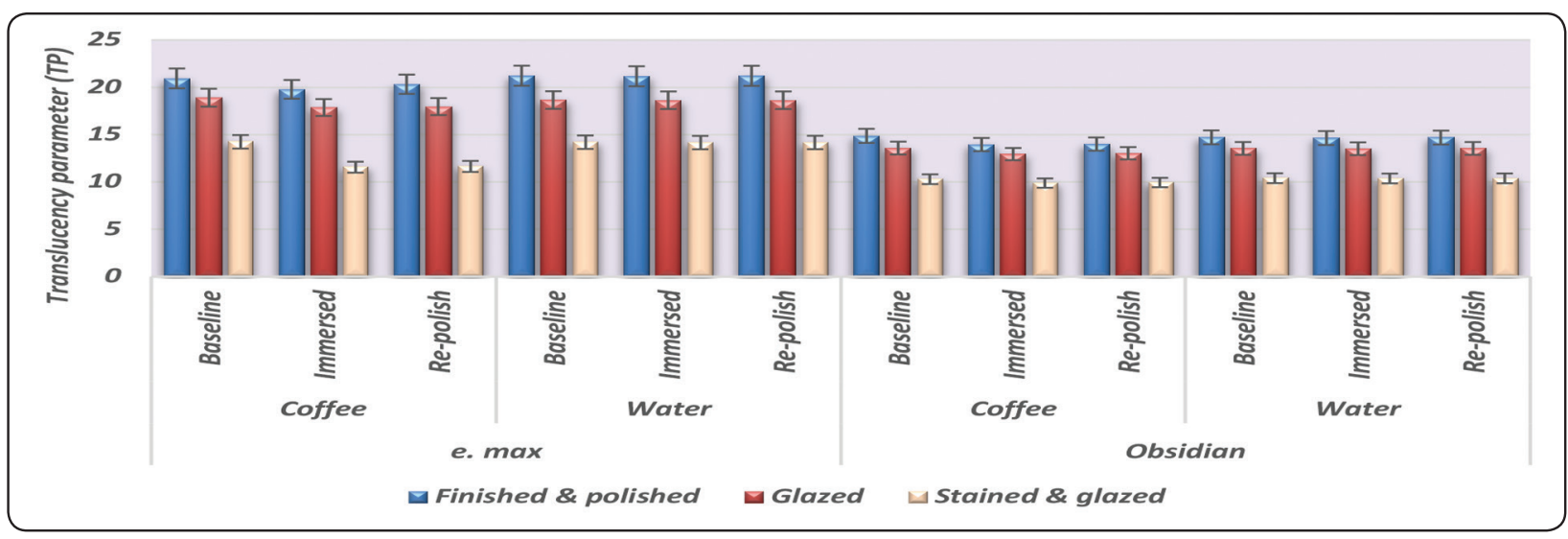

Fig. (5) Column chart showing the mean values of translucency parameter for both ceramic groups with different surface treatment after coffee, water immersion and re-polish 


\section{DISCUSSION}

The color changes and relative translucency of Obsidian and IPSe-max glass ceramics that have been subjected to different surface finishing procedures and stored in water or coffee for 18 days, were investigated in this study. The effect of polishing paste application, following 18 days coffee storage, was also tested.

Coffee has been the most commonly used staining solution in color studies followed by tea and cola. ${ }^{27,29-34}$ Among coffee drinkers; the average consumption of coffee is 3.2 cups per day. When the average time for drinking of one cup is $15 \mathrm{~min}$, the 18 days storage time simulated consumption over a one and half year period. ${ }^{27,28}$

In the present study the specimens were sectioned with the Isomet 4000. ${ }^{36,37}$ The saw cut the materials with minimal specimen deformation and low damage that can ensure standardized thickness for all 60 specimens, thus overcome any optical variations that could occur due to change in thickness. ${ }^{2}$

Many studies have founded that different chairside ceramic polishing systems have created smooth surfaces as glazing. ${ }^{38-41}$ However, type of surface finishing was an important factor in color stability. ${ }^{41-43}$ Several ceramic materials and polishing systems are now available. In the current study; polishing was performed for the specimens according to manufacturer's instructions, and regarding the evidence proving that stain resistance and color stability is improved with properly polished surfaces ${ }^{44-46}$. It was also reported that materials with different microstructures require different polishing systems.

${ }^{46}$ Each specimen was polished with the polishing kit recommended by the manufacturer to mimic the clinical condition.

Spectrophotometer can analyze the principle components of spectra and have the ability to convert spectrophotometric measures into differs values.
They have good reproducibility. Spectrophotometers have been used as a workable instrument in ${ }^{47,48}$ research to assess color stability of dental restorations, and have confirmed to be a somewhat sophisticated and accurate color measuring device ${ }^{49}$ for this reason the spectrophotometer was used in the current study.

According to the results of the study, the first null hypothesis was rejected, because the surface finishing procedures affected the color and translucency values differently. The second null hypothesis was also rejected, because the coffee solution affected the color and translucency of ceramics. The third hypothesis was also rejected, as the color change $\Delta \mathrm{E}$ values were decreased after polishing paste application.

In this study, an increase in $\Delta \mathrm{E}$ values was detected in the coffee groups for both obsidian and e-max specimens but not for specimens stored in distilled water as the control group. These groups also exceeded the TPs values of control groups. Johnston et al.$^{50}$ reported an acceptable threshold of $\Delta \mathrm{E}=3.7$. Recent studies assumed as clinically acceptable if obtained $\Delta \mathrm{E}$ values $\Delta \mathrm{E}^{*}=2$ to $4 .{ }^{51-53}$ However more recent studies reported color changes below $\Delta \mathrm{E}=1$ are unperceivable to the naked eye, and $1>\Delta E>3.3$ require a skilled person to detect the difference, thus gaining clinical acceptance. ${ }^{54}$ Therefore, the same limit was considered in this study.

The results of the current study demonstrated that glazed e-max and obsidiangroups showed statistically lower color changes with respect to the finished\& polished and stained \& glazed groups Table (2) and Fig.(4), although color change values could be clinically acceptable for both glaze and mechanical polishing methods. This similar result has also been confirmed in previous studies. ${ }^{55-57}$ Yilmaz et al ${ }^{57}$, reported that glazed ceramics revealed statistically higher color stability than ceramics polished by using polishing points and polishing 
paste, following methylene blue storage. Moreover, the results comes in consistence with the work ofMotro et al ${ }^{56}$ assessed the effects of different surface finishing techniques; glaze, reglaze, and mechanical polishing using various polishing materials, on the color stability and surface roughness of (IPS e.max Ceram) after 12 days coffee storage. The achieved higher color stability of glazed ceramics could be attributed to the glaze procedure may lead to smoother surfaces with respect to mechanical polishing methods, as smoother surfaces may result in less stain retention following storage in different beverages. Al-Wahadni A. and Martin DM. ${ }^{58}$ reported that, the glaze procedure sealing the open pores on the surface after firing, given that better optical properties and more surface smoothness, correspondingly a smooth surface reduces biofilm accumulation. While, the increase in color change in finishing and polishing group may be due to the presence of surface flaws that allow the liquids to go through while the glazed material has an impervious layer that reduce the liquid penetration. ${ }^{56,58}$

According to the result of the present study, the stained and glazed procedure groups showed statistically higher $(\Delta \mathrm{E})$ values than the glazed group after coffee storage in e-max and obsidian groups. This result is in accordance with the result of Erturk K B ${ }^{(59)}$ who attributed this to the liquid used for staining could be diluting the glazing paste, resulting in higher discoloration. Moreover ; Anil $\mathrm{N}$ et al ${ }^{60}$ and Garza LA et al, ${ }^{61}$ found that toothbrushing test have increased the surface roughness and increased color change on the externally stained ceramics. ${ }^{60,61}$ The author attributed this result to, the possibly rougher and wavier surface resulting from the brush application.

In the current study, the application of prophylactic paste after coffee storage; resulted in lower $\Delta \mathrm{E}$ values, this was in accordance with Stawarczyk et al and Kanat-Erturk $\mathrm{B}^{3}$ whom evaluated the cleaning effect of prophylactic paste, they reported that polishing with prophylaxis paste produced a decrease in color changes for the PMMA-based materials and glass-ceramic. Furthermore, all the color changes following the prophylactic paste were found below the 3.3 clinical thresholds. Consequence, the use of polishing paste in discolored ceramics may be recommended, but the effect of surface roughness following polishing needs further investigations.

In the present study; the multi-factorial ANOVA test $(p=<0.0001<0.05)$ revealed that the material had a significant effect on the translucency of both material, the e-max presented higher translucency than obsidian before and after coffee storage and after re-polishing. This result was in accordance with Hayran y, Sarıkaya I ${ }^{62}$ who were described that the difference in the TP values could be the result of the different distribution of crystals and the hardness of the material as well as the different dimensions of the ceramic material crystals. Moreover, the material composition strongly affected translucency that; the crystal content, grain size and microstructural differences in the materials are responsible for the differences in TP values. The surface structure of LDS after the crystallization process has been examined with scanning electron microscopy. ${ }^{63,64}$ and the LDS material surface showed needle-shaped crystals and an average crystal size of approximately $1.5 \mathrm{~mm}$. while the obsidian ceramic contains a high content of ultrafine nano-meter size lithium silicate and lithium phosphate crystals. ${ }^{9}$ The larger crystal dimension and higher firing temperature of e-max might explain the higher translucency of e-max than obsidian. ${ }^{65}$

In the current study; the type of surface finishing affected the translucency values of both materials before coffee storage that finished and polished groups presented the highest translucency values; table (3) and Fig. (5). This could be attributed to the glaze layer may reflect part of the incident light prisms, so the amount of light passing through 
the materials is decreased. This result of current study was in contradiction with Alp G et al ${ }^{65}$ who found that the glazed e-max group presented higher translucency than polished surfaces. Difference between the current study and those in the study by Alp $G$ et al ${ }^{65}$ may be due to the differences between the evaluated thickness of this material; the author used $1.5 \mathrm{~mm}$ while in the present study, a thickness of $1 \mathrm{~mm}$ was used for both materials. Subasi $\mathrm{G} \mathrm{M}^{66}$ found that; material thickness can be expected to affect relative translucency parameter of the restorations made from lithium disilicate ceramics.

In the present study; there is statistically significant difference between the translucency values for groups of both immersion solutions as indicated by multi-factorial ANOVA test $(p=0.0389<0.05)$ where (water >coffee). This result was consistent with Subaşı G M and Gülce $\mathrm{Alp}^{66}$, whom found a significant decrease in the translucency values for glazed groups after coffee thermocycling. Moreover; it is believed that this decrease in translucency might be because of the increased wettability of the ceramics as an outcome of the increase in the ceramic roughness caused by the acidic effects of cola, coffee, and black tea. Al-Hiyasat et al. ${ }^{67}$ reported that cola abrades several ceramics and this erosion can result in a tribochemical corrosion mechanism. Crispin and Caputo $^{68}$ have displayed that significant color change occurs on rough surfaces and decrease in TP after cola, coffee, and black tea storage. It was stated that theaflavins in tea leaves, caffeine and caffeic acid cause a color and translucency change in the ceramics. ${ }^{69}$ In contrary, Subaşı et al. ${ }^{66}$ compared the effects of material and thickness on the color stability and translucency of monolithic ceramics lithium disilicate ceramic zirconia reinforced lithium silicate ceramic, and pre-shaded monolithic zirconia exposed to coffee thermocycling. Staining in coffee did not affect the translucency of lithium disilicate ceramics. The difference between the two results could be attributed to the use of different devices for color measurement, different thickness, and different formulae for color change measurement.

However, in our study there were no statistical significance differences in translucency values in both materials and all sub groups after the application of polishing paste Table (3) and Fig.(5), this was in contradiction with Monaco C, the study that researched the prophylactic paste effect on the translucency of (IPS e.max CAD) ; it was found that the prophylactic paste application led to a decrease in translucency. ${ }^{70}$ this could be attributed to the difference in particle size of polishing paste used, function of time and pressure, hand piece speed, and thickness of the glaze layer used in both papers.

\section{CONCLUSIONS}

Within the limitations of this study, the following conclusions could be drawn:

- Staining drinks as coffee had a negative effect on the color stability and translucency of both obsidian and e-max glass ceramic materials tested.

- Glaze procedure led to more color stability with respect to mechanical polishing and external staining and glaze for both ceramics after 18days coffee storage.

- Prophylactic polishing paste led to a decrease in color changes for both ceramics tested.

- The translucency was affected according the used ceramic type. The translucency of the e.max lithium disilicate was found to be higher than that of obsidian lithium silicate glass ceramic after different finishing procedure, after coffee storage and after re-polish.

- Finished and polished groups presented the highest translucency than stained \& glazed and glazed for both ceramics tested.

- Prophylactic re-polish decreased translucency parameters non-significantly for both tested ceramics. 


\section{REFERENCES}

1. Kelly JR. Nishimura I. Campbell SD: Ceramics in dentistry: historical roots and current perspectives. J Prosthet Dent 1996;75:18-32.

2. Awad D, Stawarczyk B, Liebermann A, et al: Translucency of esthetic dental restorative CAD/CAM materials and composite resins with respect to thickness and surface roughness. J Prosthet Dent 2015;113: 534-40.

3. Stawarczyk B, Sener B, Trottmann A, et al: Discoloration of manually fabricated resins and industrially fabricated CAD/CAM blocks versus glass-ceramic: effect of storage media, duration, and subsequent polishing. Dent Mater J 2012; 31:377-383.

4. Belli R, Wendler M, de Ligny D, et al: Chairside CAD/ CAM materials. Part 1: measurement of elastic constants and microstructural characterization. Dent Mater 2017; 33: 84-98.

5. Elsaka SE, Elnaghy AM. Mechanical properties of zirconia-reinforced lithium silicate glasseceramic. Dent Mater 2016;32:908-14.(7 from 2)

6. Kelly JR, Benetti P. Ceramic materials in dentistry: historical evolution and current practice. Aust Dent J 2011; 56:84-96.

7. Pieger S, Salman A, Bidra AS. Clinical outcomes of lithium disilicate single crowns and partial fixed dental prostheses: A systematic review. J Prosthet Dent 2014; 112:22-30.

8. Niu E, Agustin M, Douglas RD. Color match of machinable lithium disilicate ceramics: effects of foundation restoration. J Prosthet Dent 2013; 110:501-509.

9. Glidewelldental.com/services/all-ceramics/obsidian-ceramic restorations.

10. Heffernan MJ, Aquilino SA, Diaz-Arnold AM, Haselton DR, Stanford CM, Vargas MA. Relative translucency of six all-ceramic systems. Part I: core materials. J Prosthet Dent 2002; 88: 4-9.

11. Lopes GC, Baratieri LN, Caldeira de Andrada MA, Maia HP. Allceramic post core, and crown: technique and case report. J Esthet Restor Dent 2001; 13: 285-95.

12. Jarad FD, Russell MD, Moss BW. The use of digital imaging for colour matching and communication in restorative dentistry. Br Dent J 2005; 199: 43-9.

13. Wee AG, Chen WY, Johnston WM. Color formulation and reproduction of opaque dental ceramic. Dent Mater 2005; 21: 665-70.
14. Clark EB. Selection of tooth color for the edentulous patient. J Am Dent Assoc. 1947; 35: 787-93.

15. Preston JD. Current status of shade selection and color matching. Quintessence Int 1985; 16: 47-58.

16. Paul SJ, Pliska P, Pietrobon N, Schärer P. Light transmission of composite luting resins. Int J Periodontics Restorative Dent 1996; 16: 164-73.11 from 16

17. Arikawa H, Fujii K, Kanie T, Inoue K. Light transmittance characteristics of light-cured composite resins. Dent Mater 1998; 14: 405-11.

18. Chen YM, Smales RJ, Yip KH, Sung WJ. Translucency and biaxial flexural strength of four ceramic core materials. Dent Mater 2008; 24: 1506-11.

19. Johnston WM. Review of translucency determinations and applications to dental materials. J Esthet Restor Dent 2014; 26: 217-23.

20. Cho MS, Lee YK, Lim BS, Lim YJ. Changes in optical properties of enamel porcelain after repeated external staining. J Prosthet Dent 2006; 95: 437-43.

21. Comlekoglu ME, Paken G, Tan F, et al: Evaluation of different thickness, die color, and resin cement shade for veneers of multilayered CAD/CAM blocks. J Prosthodont 2016; 25: 563-569.

22. Roulet JF, Roulet Mehrens TK. The surface roughnesss of restorative materials and dental tissues after polishing with prophylaxis and polishing past.j periodontal1982; 53: 257-266.

23. Neme A M, Wanger Wc, Pink FE, Frazier KB. The effect of prophylactic polishing pastes and tooth brushingon the surface roughnessof resin composite material $\mathrm{s}$ in vitro .Oper Dent 2003;28:808-815.

24. Lutz F, sener B, Imfeld T, Barbakow F, Schupbachp comparisomn of the efficacy of prpphylactic pastes with conventional abrasive or a new self adjusting abrasive. Quintessence int 1993; 24: 193-201.

25. Turgut $\mathrm{S}$, Bagis B: Colour stability of laminate veneers: an in vitro study. J Dent 2011; 39: 57-64.

26. Lee YK. Changes in the translucency of porcelain and repairing resin composite by the illumination. Dent Mater. 2007; 23: 492-7.

27. Guler AU, Kurt S, Kulunk T. Effects of various finishing procedures on the staining of provisional restorative materials. J Prosthet Dent. 2005;93:453-8.17 from 3 
28. Sarikaya I, Güler AU. Effects of different surface treatments on the color stability of various dental porcelains. J Dent Sci. 2011; 6:65-71.

29. Al Ben Ali A, Kang K, Finkelman MD, Zandparsa R, Hirayama $H$. The effect of variations in translucency and background on color differences in CAD/CAM lithium disilicate glass ceramics. J Prosthodont. 2014;23:213-20.

30. Ragain JC, Johnston WM. Minimum color differences for discriminating mismatch between composite and tooth color. J Esthet Restor Dent. 2001; 13:41-8.

31. Raimondo RL, Richardson JT, Wiedner B. Polished versus autoglazed dental porcelain. J Prosthet Dent. 1990; 64: 553-7.

32. Goldstein GR, Barnhard BR, Penugonda B. Profilometer, SEM, and visual assessment of porcelain polishing methods. J Prosthet Dent. 1991; 65: 627-34.

33. Günay Y, Atay A, Ozkan Y, Akyil MS, Karayazgan B, Toksoy F. Effect of colored beverages on the color stability of feldspathic porcelain subjected to various surface treatments. Quintessence Int. 2009; 40: 41-8.

34. Kursoglu P, Motro PFK, Kazazoglu E. Correlation of surface texture with the stainability of ceramics. J Prosthet Dent. 2014; 112: 306-13.

35. Guler AU, Yilmaz F, Kulunk T, Guler E, Kurt S. Effects of different drinks on stainability of resin composite provisional restorative materials. J Prosthet Dent. 2005; 94 : 118-24.

36. Arocha MA., et al. "Colour stainability of indirect CADCAM processed composites vs conventionally laboratory processed composites after immersion in staining solutions". Journal of Dentistry 42.7 (2014): 831-838.

37. Erdemir U., et al. "Shear bond strength of new self-adhering flowable composite resin for lithium disilicate reinforced CAD-CAM ceramic material". Journal of Advanced Prosthodontics 6.6 (2014): 434-443.

38. Goldstein GR, Barnhard BR, Penugonda B. Profilometer, SEM, and visual assessment of porcelain polishing methods. J Prosthet Dent 1991; 65: 627-34.

39. Raimondo RL Jr, Richardson JT, Wiedner B. Polished versus autoglazed dental porcelain. J Prosthet Dent 1990; 64: 553-7.

40. Al-Wahadni A, Martin DM. Glazing and finishing dental porcelain: a literature review. J Can Dent Assoc 1998; 64: 580-3.
41. Atay A, Karayazgan B, Ozkan Y, Akyil MS. Effect of colored beverages on the color stability of feldspathic porcelain subjected to various surface treatments. Quintessence Int 2009; 40: e41-8.5

42. Kursoglu P, Karagoz Motro PF, Kazazoglu E. Correlation of surfacetexture with the stainability of ceramics. JProsthet Dent, 2014;112:306-13.

43. Ragain JC Jr, Johnston WMMinimum color differences for discriminating mismatch between composite and tooth color.9.

44. Samra APB., et al. "Influence of professional prophylaxis on reducing discoloration of different aesthetic restorative materials". Journal of Dentistry 40.452 (2012): 71-76.

45. Matro PFK., et al. "Effect of different surface treatments on stainability of ceramics". Journal of Prosthetic Dentistry 108.4 (2012): 231-237.

46. Alhanouf A Alhabdan and Ahmed A El Hejazi. "Comparison of surface roughness of ceramics after polishing with different intraoral polishing systems using profilometerand SEM". Journal of Dental Health, Oral Disorders and Therapy 2.3 (2015): 1-11.

47. Da Silva JD., et al. "Clinical performance of a newly developed spectrophotometric system on tooth color reproduction”. Journal of Prosthetic Dentistry 99.5 (2008): 361-368.

48. Cal E., et al. "Comparison of digital and spectrophotometric measurements of color shade guides". Journal of Oral Rehabilitation 33.3 (2006): 221-228.

49. Chen H., et al. "A systematic review of visual and instrumental measurements for tooth shade matching". Quintessence International 43.8 (2012): 649-659.

50. Johnston W, Kao E. Assessment of appearance match by visual observation and clinical colorimetry. J Dent Res. 1989; 68: 819-22.

51. Seghi R, Johnston W, O’Brien W. Performance assessment of colorimetric devices on dental porcelains. J Dent Res. 1989; 68:1755-9.

52. Douglas RD, Brewer JD. Acceptability of shade differences in metal ceramic crowns. J Prosthet Dent. 1998; 79: 254-60.

53. Ishikawa-Nagai S, Yoshida A, Sakai M, Kristiansen J, Da Silva JD. Clinical evaluation of perceptibility of color differences between natural teeth and all-ceramic crowns. J Dent. 2009;37:57-63. 
54. Douglas RD., et al. "Intraoral determination of the tolerance of dentists for perceptibility and acceptability of shade mismatch". Journal of Prosthetic Dentistry 97.4 (2007): 200-208.

55. Stawarczyk B, Sener B, Trottmann A, et al: Discoloration of manually fabricated resins and industrially fabricated CAD/CAM blocks versus glass-ceramic: effect of storage media, duration, and subsequent polishing. Dent Mater J 2012;31:377-383.

56. Motro PF, Kursoglu P, Kazazoglu E: Effects of different surface treatments on stainability of ceramics. J Prosthet Dent 2012;108:231-237.

57. Yilmaz C, Korkmaz T, Demirk"opr"ul"u H, et al: Color stability of glazed and polished dental porcelains. J Prosthodont 2008;17:20-24.

58. Al-Wahadni A, Martin DM. Glazing and finishing dental porcelain: a literature review. J Can Dent Assoc 1998; 64: $580-3$

59. Erturk K B. Color stability of CAD CAM ceramics prepared withdifferent surface finishing procedures Journal of Prosthodontics; 00 (2019) 1-7.

60. Anil N, Bolay S: Effect of toothbrushing on the material loss, roughness, and color of intrinsically and extrinsically stained porcelain used in metal-ceramic restorations: an in vitro study. Int J Prosthodont 2002; 15: 483-487.

61. Garza LA, Thompson G, Cho SH, et al: Effect of toothbrushing on shade and surface roughness of extrinsically stained pressable ceramics. J Prosthet Dent 2016; 115: 489-494.
62. Hayran Y,Sarıkaya I: Effect of Different Surface Finishing Methods and Colorant Solutions on Translucency of Monolithic CAD/CAM Ceramics. Meandros Med Dent J; 2019;20:144-51

63. Cho MS, Lee YK, Lim BS, Lim YJ. Changes in optical properties of enamel porcelain after repeated external staining. J Prosthet Dent 2006; 95: 437-43.

64. Weitman RT, Eames WB. Plaque accumulation on composite surfaces after various finising procedures. J Am Dent Assoc 1975; 91: 101-6.16 from 16

65. Gulce Alp, Meryem Gulce Subasi,William M. Johnston, and Burak Yilmaz.Effect of surface treatments and coffee thermocycling on the color and translucency of CADCAM monolithic glass-ceramic J Prosthet Dent 2018

66. Subaşı MG, Alp G, Johnston WM, Yilmaz B. Effect of thickness on optical properties of monolithic CAD-CAM ceramics. J Dent 2018; 71:38-42.

67. Al-Hiyasat AS, Saunders WP, Sharkey SW, Smith GM. The effect of a carbonated beverage on the wear of human enamel and dental ceramics. J Prosthodont 1998; 7: 2-12.

68. Crispin BJ, Caputo AA. Color stability of temporary restorative materials. J Prosthet Dent 1979; 42: 27-33.

69. Keskin IS. The treatment of prosthetic dental materials with hypochlorite. Ankara: Middle East Technical Univ. 2002.

70. Monaco C, Arena A, O” zcan M: Effect of prophylactic polishing pastes on roughness and translucency of lithium disilicate ceramic. Int $\mathbf{J}$ Periodontics Restorative Dent 2014; 34: 26-29. 